\title{
NEUROMOTOR AND FUNCTIONAL OUTCOMES IN PATIENTS WITH SICKLE CELL DISEASE AND STROKE (ABSTRACT)*. DISSERTATION. CAMPINAS, 2008
}

\section{CAROLINA CAMARGO DE OLIVEIRA**}

Patients with Sickle Cell Disease (SCD) have a high risk for stroke with important neurological sequelae. Many authors have been pointing the neuropsychological impairment but not the motor and functional deficits.

The aim of this study was to assess patients with and stroke comparing with patients with SCD without stroke.

We pre-selected patients with ages ranging form 5 to 25 years and diagnosis of SCD and stroke for the experimental group (EG), and without stroke for the control group (CG). Overall, 15 patients were enrolled, of whom 10 were in $E G$ and 5 in CG. Patients and their parents were informed about the research objectives and procedures and agreed to participate by signing a free consent agreement form. A protocol was organized including identification data, neurological clinical exam, neurological imaging screening; neuromotor and function assessment.

The identification and history of SCD and the cerebrovascular event data were collected from records and completed with an interview of patients and their parents. The patients were assessed with neuromotor scales and the following function instruments: PEDI and EB test. In EG patients, the first stroke occurred with high incidence between 4 and 15 years of age; despite the low number of individuals evaluated, findings are in accordance with previously published, evidencing patients with $S C D$ and stroke in early age, all with ischemic event; 2 patients had recurrence of stroke despite prophylactic blood transfusion therapy. The analysis of the results of this study revealed important neuromotor deficits in EG; superior performance in functional instruments of the CG, especially in gross motor function, global strength; rang of motion; neurological tests; sensory and grasp. The muscle tonus and strength interfered with sensory, gross and fine motor function, neurological exam; perception; range of motion; and grasp.

The motor, sensorial and function impairments resulting from cortical-subcortical structure lesions were confirmed by neurologic imaging exams, especially involving middle cerebral artery, perforating branches and anterior cerebral artery. Therefore, these neuromotor and functional findings in EP and also in CG justify to include these assessments and neurological imaging screening in patients with SCD, even in those without stroke. This may help to identify risk factors, improving prophylaxis for the first stroke or its recurrence, as well as the rehabilitation after stroke.

Key words: physical therapy, motor skills, sickle cell, stroke.

*Avaliação Neuromotora e Funcional de Pacientes com Doença Falciforme e Acidente Vascular Cerebral. Dissertação de Mestrado. Faculdade de Ciências Médicas da Universidade Estadual de Campinas (Mestre em Ciências Médicas; Área de concentração: Ciências Biomédicas). Orientador: Maria Valeriana Leme de Moura Ribeiro.

**Address: Departamento de Neurologia FCM / UNICAMP - Cx. Postal: 6111 - 13083-970 Campinas SP - Brasil (E-mail: ccamargoofisio@yahoo.com.br). 